\title{
Saturated Polar-Substituted Polyethylene Elastomers from Insertion Polymerization
}

\author{
Thomas Rünzi and Stefan Mecking*
}

Saturated, polar-substituted elastomers consisting of a linear polyethylene backbone are prepared directly by insertion copolymerization of ethylene with polar-functionalized vinyl monomers employing functional-group tolerant catalysis. This unprecedented approach to elastomers is compatible with a wide range of different crosslinking chemistries. Crosslinking of the materials occurs efficiently, as concluded from gel contents and spectroscopic observations. Mechanical and thermal properties are revealed by dynamic mechanical analysis.

for this purpose. While this reaction is run on a large scale, it is technically and economically very demanding. Depending on the degree of hydrogenation, completely hydrogenated material $(>99 \%)$ is crosslinked with peroxides or radiation or in case of partial hydrogenation $(<99 \%)$, crosslinking is performed with sulfur. Another option is the direct free-radical copolymerization of polar monomers with ethylene. Prominent representatives are ethylene-vinyl acetate rubbers (EVM), typically consisting of 40 to $80 \mathrm{wt} \%$ of vinyl

\section{Introduction}

Elastomers are used for a myriad of applications, and virtually any technical system comprises elastomers as an essential component. Examples are tires and pulleys, seals and gaskets, power transmission and conveyor belts to name only a few. Ethylene-propylene rubbers (EPR) and ethylene-propylene-diene monomer-rubbers (EPDM) are widely used rubbers exhibiting a fully saturated hydrocarbon backbone. Due to the saturated backbone, these materials e.g. possess an outstanding ozone resistance. In terms of solvent resistance, they are sufficiently resistant towards polar organic and inorganic compounds. However, they are prone to swelling in aliphatic compounds such as oils, fats or fuel. Exposure to such apolar liquids is ubiquitous in many applications e.g. automotives. To overcome this drawback, incorporation of polar moieties is desirable. The catalysts used for the production of EPRs are based on early transition metals, such as vanadium or titanium catalysts. Due to their high oxophilicity, the active sites are irreversibly deactivated by heteroatom-containing polar monomers. In contrast to EPR, free-radically produced acrylonitrile-butadiene rubbers (NBR) exhibit excellent resistance towards apolar compounds. However, the butadiene-derived repeat units contain a residual double bond which is subject to undesired aging in applications..$^{[1]}$ Thus, a post-polymerization hydrogenation is necessary (HNBR) to enhance their stability for applications as high performance materials under harsh environmental conditions. Homogenous rhodium or ruthenium catalysts are used

\footnotetext{
T. Rünzi, Prof. S. Mecking

Chair of Chemical Materials Science

Department of Chemistry

University of Konstanz

Universitätsstrasse 10, 78457, Konstanz, Germany

E-mail: Stefan.mecking@uni-konstanz.de
}

acetate, or ethylene-acrylate rubbers (AEM) (representative composition: $41 \mathrm{~mol} \%$ of ethylene, 55 mol-\% of acrylate and 4 mol\% of a carboxylic acid containing monomer). Harsh reaction conditions are required for polymerization (up to 3000 bar and 150 to $350{ }^{\circ} \mathrm{C}$ ), and there is practically very little opportunity for contolling the polymer microstructure such as branching.

An alternative to the two-step polymerization and post-polymerization modification procedure for the synthesis of HNBR or to the high-pressure polymerization techniques employed for EVM and AEM would be the direct synthesis of saturated polar-substituted rubbers by catalytic polymerization. With respect to the challenging issue of insertion polymerization of polar vinyl monomers, substantial advances have been made most recently. Neutral phosphinesulfonato $\mathrm{Pd}(\mathrm{II})$ catalysts were found to be compatible with a broad scope of polar substituted monomers ${ }^{[2-7]}$ in ethylene copolymerizations, comprising even acrylonitrile, ${ }^{[8]}$ vinyl acetate ${ }^{[9]}$ and acrylic acid. ${ }^{[10,11]}$ To date, such copolymerizations have not been studied with regard to tailoring material properties. We now report a direct route via insertion polymerization to saturated polyethylene-based materials containing polar and crosslinkable groups and the properties of the resulting elastomers.

\section{Results and Discussion}

Concerning the introduction of hitherto unexplored substituents and reactive groups in polar vinyl comonomers, their compatibility with the insertion polymerization catalyst is essential. In addition, a knowledge of relative insertion reactivities is advantageous to choose appropriate polymerization conditions. All monomers employed were preliminarily examined in stoichiometric NMR scale experiments for their reactivity towards the catalyst precursor used, 1-dmso (Scheme 1). In a typical experiment, 1-dmso $\left(30 \mathrm{mM}\right.$ in $\mathrm{CD}_{2} \mathrm{Cl}_{2}$ ) was exposed to a ca. 20 -fold excess of monomer at room temperature and 

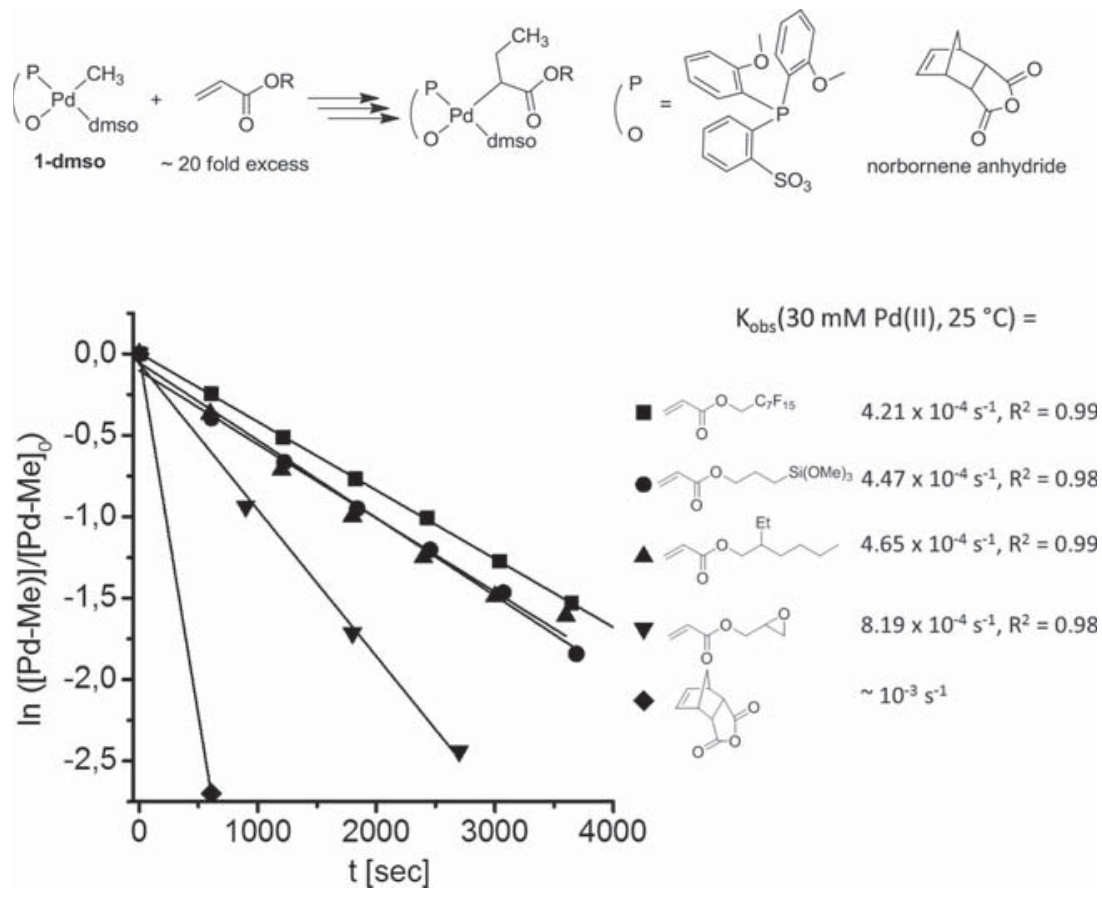

Scheme 1. Insertion studies of 1-dmso with various vinylic comonomers.

the insertion was recorded by periodically acquired ${ }^{1} \mathrm{H}$ NMR spectra. The excess of monomer allows for the extraction of a pseudo first-order rate constant, which is an overall rate constant including a prequilibrium $\left[\left(\mathbf{P}^{\wedge} \mathbf{O}\right) \mathbf{P d M e}(\mathbf{d m s o})\right]+$ vinyl monomer $\rightleftarrows\left[\left(\mathbf{P}^{\wedge} \mathbf{O}\right) \mathbf{P d M e}(\right.$ vinyl monomer $\left.)\right]+$ dmso preceeding insertion. In all cases, insertion occurs predominantly in a 2,1-fashion as illustrated in Scheme 1. The characteristic resonances for the 2,1-insertion product, exemplified for the insertion of fluoro acrylate, are a triplet at $\delta\left({ }^{1} \mathrm{H}\right) 0.28 \mathrm{ppm}$ for the methyl group which is coupled with ${ }^{3} \mathrm{~J}_{\mathrm{HH}}=7 \mathrm{~Hz}$ to the adjacent methylene group. The latter possesses diastereotopic protons at $\delta 0.85 \mathrm{ppm}$ and $1.40 \mathrm{ppm}$. The $\alpha$-methine resonates at $\delta 1.72 \mathrm{ppm}$. Only minor traces $(<3 \%)$ of the 1,2-insertion product are observed which gives rise to a characteristic doublet resonance at $\delta\left({ }^{1} \mathrm{H}\right) \sim 1.1 \mathrm{ppm}$, coupled to an adjacent methine group. ${ }^{[12]}$ Furthermore, the resonance for the dmso -which is low-field shifted upon coordination to palladium- remains low-field shifted after complete conversion of the Pd-Me of 1-dmso, e.g. dmso resonates at $\delta\left({ }^{1} \mathrm{H}\right) 2.94 \mathrm{ppm}$ in 1-dmso and is up-field shifted after insertion to $\delta\left({ }^{1} \mathrm{H}\right) 2.81 \mathrm{ppm}$ vs. free dmso $\left(\delta\left({ }^{1} \mathrm{H}\right) 2.54 \mathrm{ppm}\right.$ in $\left.\mathrm{CD}_{2} \mathrm{Cl}_{2}\right)$. This indicates that the dmso introduced with the catalyst precursor 1-dmso is coordinated to the metal center also in the insertion product (Figure S1 and S2). Fluoro acrylate, 2-ethyl hexyl acrylate and siloxane acrylate insert with similar net rates in the range of $\mathrm{k}_{\text {obs }}\left(25^{\circ} \mathrm{C}, 30 \mathrm{mM} \mathrm{Pd}(\mathrm{II})\right)=3.25 \times 10^{-4} \mathrm{~s}^{-1}$ to $4.65 \times 10^{-4} \mathrm{~s}^{-1}$. Glycidyl acrylate possesses slightly higher insertion rates with $\mathrm{k}_{\mathrm{obs}}\left(25^{\circ} \mathrm{C}, 30 \mathrm{mM} \mathrm{Pd}(\mathrm{II})\right)=8.19 \times 10^{-4} \mathrm{~s}^{-1}$ (Scheme 1). All in all, the insertion rates for the acrylic monomers do not differ strongly from the rate found for the insertion of methyl acrylate under otherwise identical conditions, which suggests that the additional functional groups do not adversely affect insertion of these acrylates $\left(\mathrm{k}_{\mathrm{obs}}\left(25^{\circ} \mathrm{C}, 30 \mathrm{mM}\right.\right.$

Table 1. Co- and Terpolymerization of ethylene with fluoro acrylate and siloxane acrylate. ${ }^{\text {a) }}$

\begin{tabular}{|c|c|c|c|c|c|c|c|c|c|c|c|c|}
\hline Entry & $\begin{array}{c}\text { Concn. } \\
\text { (Fluoro } \\
\text { acrylate) } \\
{[\mathrm{M}]} \\
\end{array}$ & $\begin{array}{c}\text { Concn. } \\
\text { (Siloxane acrylate) } \\
{[\mathrm{M}]}\end{array}$ & $\begin{array}{l}\operatorname{Pd}(\mathrm{II}) \\
{[\mu \mathrm{mol}]}\end{array}$ & $\begin{array}{l}\text { Polym. Time } \\
\text { [min] }\end{array}$ & $\begin{array}{c}\text { Yield } \\
{[\mathrm{g}]}\end{array}$ & $\begin{array}{c}\text { TOF } \\
\left(\mathrm{C}_{2} \mathrm{H}_{4}\right)^{\mathrm{e})}\end{array}$ & $\begin{array}{c}\text { TOF } \\
\text { (Fluoro } \\
\text { acrylate) }\end{array}$ & $\begin{array}{c}\text { TOF } \\
\text { (Siloxane } \\
\text { acrylate)e) }\end{array}$ & $\begin{array}{l}\text { Inc. (Fluoro } \\
\text { acrylate) } \\
{[\text { mol\% }]^{\text {b) }}}\end{array}$ & $\begin{array}{c}\text { Inc. } \\
\text { (Siloxane acrylate) } \\
{[\text { mol\% }]^{\text {b) }}}\end{array}$ & $\begin{array}{l}\mathrm{M}_{\mathrm{n}}(\mathrm{NMR}) \\
{\left[\mathrm{g} \mathrm{mol}^{-1}\right]^{\mathrm{c})}}\end{array}$ & $\begin{array}{l}\text { Gel Content } \\
{[\%]^{d)}}\end{array}$ \\
\hline 1 & 0.25 & - & 10 & 60 & 1.25 & 3040 & 90 & - & 2.8 & - & 5700 & - \\
\hline 2 & 0.50 & - & 10 & 60 & 0.99 & 1700 & 110 & - & 6.1 & - & 4200 & - \\
\hline 3 & 1.00 & - & 10 & 60 & 0.52 & 530 & 80 & - & 13.3 & - & 3600 & - \\
\hline 4 & - & 0.25 & 20 & 60 & 1.64 & 2140 & - & 90 & - & 4.2 & 7200 & 57 \\
\hline 5 & - & 0.50 & 20 & 60 & 0.94 & 1000 & - & 80 & - & 7.3 & 5900 & 97 \\
\hline 6 & - & 0.75 & 20 & 60 & 0.61 & 490 & - & 70 & - & 12.9 & 6100 & n.m. \\
\hline 7 & 0.30 & 0.30 & 50 & 120 & 4.08 & 700 & 39 & 34 & 3.8 & 4.5 & 6000 & n.m. \\
\hline 8 & 0.50 & 0.50 & 70 & 120 & 3.92 & 320 & 26 & 30 & 6.9 & 8.0 & 8500 & 98 \\
\hline
\end{tabular}

a) Polymerization conditions: 1-dmso in $0.6 \mathrm{~mL} \mathrm{CH} \mathrm{Cl}_{2}$ stock solution; Entry 1-3 in $5 \mathrm{~mL}$ total volume (toluene + acrylates) with $10 \mathrm{mg}$ BHT added, entry 4-8 in $50 \mathrm{~mL}$ total volume (toluene + acrylates) with $30 \mathrm{mg} \mathrm{BHT}$ added, $95^{\circ} \mathrm{C}$ reaction temperature; ${ }^{b}$ Determined by ${ }^{1} \mathrm{H}$ NMR spectroscopy; ${ }^{\circ}$ Determined from ${ }^{1} \mathrm{H}$ NMR assuming that every polymer chain contains of one aliphatic and one olefinic chain end; ${ }^{d}$ Gel content after crosslinking, $n . m .:$ not measured; ${ }^{e}$ TOF $=$ mol (monomer polymerized) $m o l(P d)^{-1} h^{-1}$. 
$\operatorname{Pd}(\mathrm{II}))=6.67 \times 10^{-4} \mathrm{~s}^{-1}$ for methyl acrylate). $\mathrm{A}$ considerably faster insertion into 1-dmso was found for norbornene anhydride as a strained reactive olefin. Conversion of $\mathrm{Pd}-\mathrm{Me}$ was already complete after less than 5 minutes at $25^{\circ} \mathrm{C}$ which corresponds to an insertion rate of $\mathrm{k}_{\mathrm{obs}}\left(25^{\circ} \mathrm{C}, 30 \mathrm{mM} \mathrm{Pd}(\mathrm{II})\right)$ of ca $10^{-3} \mathrm{~s}^{-1}$. Note that the preferred insertion mode for norbornenes is generally the exo-insertion. ${ }^{[13]}$ The ${ }^{1} \mathrm{H}$ NMR spectrum of the insertion product does, however, not allow for a conclusion on this issue as all indicative resonances are broadened and no coupling constants could be determined. Reported NOE transfer experiments on ethylene copolymers were interpreted towards an endo-insertion. ${ }^{[10 b]}$ For the monomers bearing reactive substituents for crosslinking, the NMR experiments show that the monomers with atrimethoxysilyl, glycidyl and anhydride moiety are inert in the presence of the catalyst.

\subsection{Siloxane-Crosslinked Elastomers}

As anticipated from the aforementioned findings, exposure of 1-dmso to ethylene and the perfluorinated acrylate under polymerization conditions resulted in the formation of polymer. Comonomer contents up to $13.3 \mathrm{~mol} \%$ were achieved (Table 1 ), corresponding to a fluorine content of $71 \mathrm{wt} \%$ of the copolymer. The distinct ${ }^{13} \mathrm{C}$ NMR resonances $\left(130{ }^{\circ} \mathrm{C}, \mathrm{C}_{2} \mathrm{D}_{2} \mathrm{Cl}_{4}\right)$ of the methylene carbons adjacent to the carbonyl group $-\mathrm{C}^{\beta} \mathrm{H}_{2} C^{\alpha} \mathrm{H}_{2} \mathrm{CH}\left(\mathrm{COO}\left(\mathrm{CH}_{2}-\mathrm{C}_{7} \mathrm{~F}_{15}\right)\right) C^{\alpha} \mathrm{H}_{2} C^{\beta} \mathrm{H}_{2}-$ at $\delta 32.53(\alpha)$ and $27.63(\beta)$ evidence the incorporation of the acrylate into the polyethylene backbone. The methylene moiety next to the perfluorinated alkyl resonating at $\delta 55.69 \mathrm{ppm}$ with ${ }^{2} J_{\mathrm{CF}}=29.6 \mathrm{~Hz}$ and $\delta 4.64 \mathrm{ppm}$ with ${ }^{3} J_{\mathrm{HF}}=13.0 \mathrm{~Hz}$ in ${ }^{1} \mathrm{H} \mathrm{NMR}$, respectively, represents an additional characteristic resonance in poly(ethylene-co-fluoro acrylate) (Figure S4-6).

Copolymerization of ethylene with the crosslinkable siloxane acrylate was studied. The copolymers exhibit the characteristic resonances, $\mathrm{C}^{\alpha}$ and $\mathrm{C}^{\beta}$, in ${ }^{13} \mathrm{C}$ NMR spectroscopy at $\delta 32.80$ and $27.84 \mathrm{ppm}$ similar to poly(ethylene-co-fluoro acrylate) (Figure S10). Further, the characteristic high-field shifted ${ }^{1} \mathrm{H}$ and ${ }^{13} \mathrm{C}$ resonance at $\delta 0.73$ and $\delta 6.21 \mathrm{ppm}$, respectively, for the methylene group adjacent to the $-\mathrm{Si}(\mathrm{OMe})_{3}$ in combination with the Si-OMe ${ }^{1} \mathrm{H}$ resonance at $\delta 3.62 \mathrm{ppm}$ evidences the absence of any hydrolysis of the Si-OMe moieties during polymerization or workup (Figure S8+S9). This is further confirmed by the complete solubility of the copolymers in $\mathrm{C}_{2} \mathrm{D}_{2} \mathrm{Cl}_{4}$ at $130{ }^{\circ} \mathrm{C}$. The ATR-IR spectrum of a typical copolymer of ethylene and siloxane acrylate exhibits characteristic absorption bands at $1190 \mathrm{~cm}^{-1}$ (rock vib), $1081 \mathrm{~cm}^{-1}$ (asym stretch) and $822 \mathrm{~cm}^{-1}$ (sym stretch) for the $\mathrm{Si}(\mathrm{OMe})_{3}$ group.

${ }^{13} \mathrm{C}\left\{{ }^{1} \mathrm{H}\right\}$ NMR spectra of the terpolymers poly(ethylene-cofluoro acrylate-co-siloxane acrylate) (Table 1, entry 7 and 8) in $\mathrm{C}_{2} \mathrm{D}_{2} \mathrm{Cl}_{4}$ at $130{ }^{\circ} \mathrm{C}$ possess the characteristic resonances adjacent to the esters that confirm the incorporation of both acrylates into the polyethylene backbone (Figure 1). In addition, gel permeation chromatography (GPC) of the terpolymer with $6.9 \mathrm{~mol} \%$ fluoro acrylate and $8.0 \mathrm{~mol} \%$ siloxane acrylate (Table 1, entry 8) showed a monomodal molecular weight distribution $\left(\mathrm{M}_{\mathrm{n}}=7700 \mathrm{~g} \mathrm{~mol}^{-1}, \mathrm{M}_{\mathrm{w}} / \mathrm{M}_{\mathrm{n}}=1.2\right.$, vs. polystyrene standards $)$. This molecular weight is in good agreement with the molecular weight of $8500 \mathrm{~g} \mathrm{~mol}^{-1}$ determined from the ratio of olefinic endgroups to aliphatic resonances from ${ }^{1} \mathrm{H}$ NMR assuming one saturated end group per chain (also cf. reference 14).

Crosslinking of the polymers obtained was performed in toluene solution at $100{ }^{\circ} \mathrm{C}$ by addition of small amounts of water and catalytic amounts of para-toluenesulfonic acid to initiate hydrolysis of the $-\mathrm{Si}(\mathrm{OMe})_{3}$ moieties. The crosslinked terpolymer poly(ethylene-co-fluoro acrylate-co-siloxane acrylate) (Table 1, entry 7) was subjected to high temperature ${ }^{1} \mathrm{H}$ NMR spectroscopy on polymer gel swollen with $\mathrm{C}_{2} \mathrm{D}_{2} \mathrm{Cl}_{4}$ at $130{ }^{\circ} \mathrm{C}$. As expected, ${ }^{1} \mathrm{H}$ resonances appear broadened in comparison to the spectrum of the non-crosslinked polymer. The complete absence of the methoxy resonances is evidence for a full hydrolysis of the $\mathrm{Si}(\mathrm{OMe})_{3}$ (Figure S13). This is further evidenced by ATR-IR spectroscopy where the characteristic absorptions for 
Table 2. Co- and terpolymerization of ethylene with glycidyl acrylate, 2-ethyl hexyl acrylate and fluoro acrylate. ${ }^{\text {a) }}$

\begin{tabular}{|c|c|c|c|c|c|c|c|c|c|c|c|c|c|c|c|}
\hline Entry & $\begin{array}{c}\text { Concn. } \\
\text { (Glycidyl } \\
\text { acrylate) } \\
{[\mathrm{M}]}\end{array}$ & $\begin{array}{c}\text { Concn. } \\
\text { (EtHex } \\
\text { acrylate) } \\
{[\mathrm{M}]}\end{array}$ & $\begin{array}{c}\text { Concn. } \\
\text { (Fluoro } \\
\text { acrylate) } \\
{[\mathrm{M}]}\end{array}$ & $\begin{array}{l}\mathrm{Pd}(\mathrm{II}) \\
{[\mu \mathrm{mol}]}\end{array}$ & $\begin{array}{l}\mathrm{C}_{2} \mathrm{H}_{4} \\
\text { [bar] }\end{array}$ & $\begin{array}{l}\text { Polym. } \\
\text { Time } \\
\text { [min] }\end{array}$ & $\begin{array}{l}\text { Yield } \\
\text { [g] }\end{array}$ & $\begin{array}{c}\text { TOF } \\
\left(\mathrm{C}_{2} \mathrm{H}_{4}\right)^{\text {d) }}\end{array}$ & $\begin{array}{c}\text { TOF } \\
\text { (Glycidyl } \\
\text { acrylate) }{ }^{\text {d) }}\end{array}$ & $\begin{array}{l}\text { TOF (EtHex } \\
\text { acrylate) })^{\text {d) }}\end{array}$ & 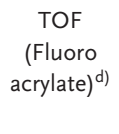 & $\begin{array}{c}\text { Inc. } \\
\text { (Glycidyl } \\
\text { acrylate) } \\
{[\text { mol\%] }}\end{array}$ & $\begin{array}{c}\text { Inc. } \\
\text { (EtHex } \\
\text { acrylate) } \\
{[\text { mol\% }]^{\text {b) }}}\end{array}$ & $\begin{array}{c}\text { Inc. } \\
\text { (Fluoro } \\
\text { acrylate) } \\
{[\mathrm{mol} /]^{b)}}\end{array}$ & $\begin{array}{l}\mathrm{M}_{\mathrm{n}}(\mathrm{NMR}) \\
{\left[\mathrm{g} \mathrm{mol}^{-1}\right]^{\mathrm{c})}}\end{array}$ \\
\hline 1 & - & 0.3 & - & 20 & 5 & 60 & 2.35 & 3290 & - & 170 & - & - & 4.8 & - & 6000 \\
\hline 2 & 0.1 & - & - & 20 & 5 & 60 & 0.91 & 1480 & 32 & - & - & 2.1 & - & - & 5400 \\
\hline 3 & 0.3 & - & - & 20 & 5 & 60 & 0.35 & 460 & 34 & - & - & 6.9 & - & - & 5400 \\
\hline 4 & 0.6 & - & - & 20 & 5 & 60 & 0.21 & 230 & 30 & - & - & 11.4 & - & - & 5700 \\
\hline 5 & 1.2 & 2.4 & - & 133 & 20 & 120 & 4.50 & 3160 & 210 & 290 & - & 5.8 & 7.9 & - & 8200 \\
\hline 6 & 0.6 & 0.6 & 0.6 & 90 & 10 & 120 & 6.2 & 4860 & 360 & 250 & 260 & 6.5 & 4.6 & 4.7 & 7700 \\
\hline
\end{tabular}

a) Polymerization conditions: 1-dmso in $0.6 \mathrm{~mL} \mathrm{CH} \mathrm{Cl}_{2}$ stock solution; $95{ }^{\circ} \mathrm{C}$ reaction temperature; $100 \mathrm{~mL}$ total volume (toluene + acrylates); b) Determined by ${ }^{1} \mathrm{H} \mathrm{NMR}$ spectroscopy; ${ }^{\mathrm{c}}$ Determined from ${ }^{1} \mathrm{H}$ NMR assuming that every polymer chain contains of one aliphatic and one olefinic chain end; ${ }^{\mathrm{d}} \mathrm{TOF}=$ mol(monomer polymerized) $\mathrm{mol}(\mathrm{Pd})^{-1} \mathrm{~h}^{-1}$.

the $-\mathrm{Si}(\mathrm{OMe})_{3}$ are replaced by a broad absorption for -Si-O-Si- or -Si-OH moieties around $1100 \mathrm{~cm}^{-1}$ (Figure S14).

Determination of the gel content with boiling xylenes of an ethylene copolymer with $7.3 \mathrm{~mol} \%$ of incorporated siloxane after crosslinking (Table 1, entry 5) revealed an insoluble fraction of $97 \pm 5 \%$, that is, within the error of this method, crosslinking is complete. ${ }^{[15]}$ Likewise, crosslinking under identical conditions of a poly(ethylene-co-siloxane acrylate-co-fluoro acrylate) with $6.9 \mathrm{~mol} \%$ of fluoro acrylate and $8.0 \mathrm{~mol} \%$ of siloxane acrylate (entry 8 ) resulted in insoluble rubbery material with an insoluble fraction of $98 \pm 5 \%$.

\subsection{Glycidyl-Crosslinked Elastomers}

2-Ethyl hexyl acrylate, which is used in order to reduce crystallinity was investigated in copolymerization of ethylene under identical conditions. The corresponding $\alpha \delta^{+} 3$ and $\beta \delta^{+} 3$ resonances for the incorporated 2-ethyl hexyl acrylate (Table 2, entry 1) were detected at $\delta\left({ }^{13} \mathrm{C}\right) 31.84 \mathrm{ppm}$ and $27.87 \mathrm{ppm}$ (Figure S16).

Glycidyl moieties are a very versatile functionality. The reaction of glycidyls with amines is e.g. the basis for epoxy resins. ${ }^{[16]}$ For this reason, copolymerizations of glycidyl acrylate with ethylene (Table 2, entry 2-4) were performed. ${ }^{1} \mathrm{H}$ and ${ }^{13} \mathrm{C}\left\{{ }^{1} \mathrm{H}\right\}$ NMR $\left(\mathrm{C}_{2} \mathrm{D}_{2} \mathrm{Cl}_{4}, 130{ }^{\circ} \mathrm{C}\right)$ analyses of the polymers obtained confirm the stability of the glycidyl group under insertion polymerization conditions. ${ }^{1} \mathrm{H}$ NMR spectra feature diastereotopic resonances for the methylene adjacent to the ester at $\delta\left({ }^{1} \mathrm{H}\right) 4.38$ and $4.05 \mathrm{ppm}$ bound to a carbon at $\delta\left({ }^{13} \mathrm{C}\right) 64.77 \mathrm{ppm}$ for $\alpha^{\prime \prime}$ and $\delta\left({ }^{1} \mathrm{H}\right) 2.83$ and $2.66 \mathrm{ppm}$ for the methylene moiety $\gamma^{\prime \prime}\left(\delta\left({ }^{13} \mathrm{C}\right)\right.$ 45.00 ) of the epoxide (Figure S17+S18). The characteristic resonances of the methylene groups adjacent to the incorporated ester ( $\alpha \delta^{+} 4 \delta 32.77 \mathrm{ppm}$ and $\left.\beta \delta^{+} 4 \delta 27.84 \mathrm{ppm}\right)$ confirm the copolymer structure. These key resonances were also found in the polymers poly(ethylene-co-2-ethyl hexyl acrylate-co-glycidyl acrylate) and poly(ethylene-co-2-ethyl hexyl acrylate-co-fluoro acrylate-co-glycidyl acrylate) (Figure S20-22) which in addition possess monomodal GPC traces with $\mathrm{M}_{\mathrm{n}} 8500 \mathrm{~g} \mathrm{~mol}^{-1} ; \mathrm{M}_{\mathrm{w}} / \mathrm{M}_{\mathrm{n}}$ 1.5 and $\mathrm{M}_{\mathrm{n}} 8300 \mathrm{~g} \mathrm{~mol}^{-1} ; \mathrm{M}_{\mathrm{w}} / \mathrm{M}_{\mathrm{n}}$ 1.4, respectively (Table 2, entry 5 and 6).

For crosslinking experiments, an ethylene copolymer containing 6.9 mol\% of glycidyl substituted repeat units (Table 2, entry 3) was dissolved in xylenes, and 1,12-dodecane diamine was added in an $-\mathrm{NH}_{2}$ :glycidyl ratio of $1: 1$. The mixture was heated for $2 \mathrm{~h}$ to $140^{\circ} \mathrm{C}$. Within this time, the polymer gelated. Conversion of the crosslinked polymer was investigated by ATR-IR spectroscopy. The peaks at $909 \mathrm{~cm}^{-1}$ and $846 \mathrm{~cm}^{-1}$ are attributed to the asymmetric and symmetric ring deformation vibration of the epoxide ring and are strongly reduced in intensity in the crosslinked material (Figure S23). ${ }^{[17-19]}$ Note that the glycidyl moieties are not entirely converted, which can be ascribed to a limited mobility of the residual groups or by inaccuracy of the equivalents of diamine. The gel content of this copolymer was determined to be $94 \pm 5 \%$. Crosslinking of the terpolymers poly(ethylene-co-2-ethyl hexyl acrylate-co-glycidyl acrylate) and poly(ethylene-co-2-ethyl hexyl acrylate-co-fluoro acrylate-co-glycidyl acrylate) (Table 2, entry 5 and 6) under identical conditions results in formation of rubbery materials. The corresponding gel contents are $99 \pm 5 \%$ and $98 \pm 5 \%$, respectively. Again, the glycidyl moieties are not entirely converted as evidenced by the characteristic bands in ATR-IR spectrum.

\subsection{Azide-Alkine-Crosslinked Elastomers}

Despite the broad scope of polar moieties that are tolerated by phosphinesulfonato $\mathrm{Pd}(\mathrm{II})$ catalysts, azide-substituted acrylates $\left(\mathrm{CH}_{2}=\mathrm{CHCOO}-\mathrm{C}_{6} \mathrm{H}_{12}-\mathrm{N}_{3}\right)$ and 1-olefins $\left(\mathrm{CH}_{2}=\mathrm{CH}-\mathrm{C}_{3} \mathrm{H}_{6}-\mathrm{N}_{3}\right)$ were 


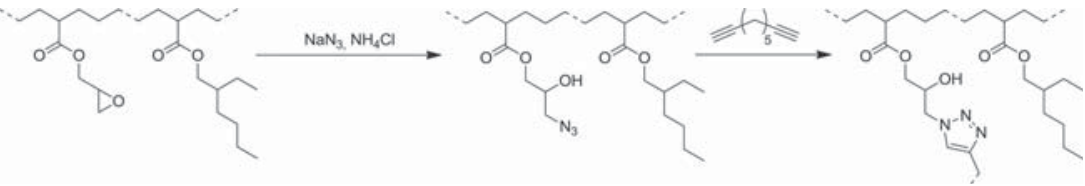

Scheme 2. Polymer-analogous azidation of poly(ethylene-co-2-ethyl hexyl acrylate-co-glycidyl acrylate) and subsequent click-crosslinking with nona-1,8-diyne. the polymer remaining sticky for the first few hours, but eventually the material turns rubbery after an overall $18 \mathrm{~h}$ at $90^{\circ} \mathrm{C}$. Gel contents were determined by extracting the crosslinked polymers with hot xylenes. The copper-promoted crosslinked polymer exhibited $98 \pm$ $5 \%$ insoluble fractions while the copper-free crosslinked material is insoluble to $90 \pm 5 \%$. found to hamper copolymerization with ethylene under standard polymerization conditions ( 5 bar ethylene, $0.05 \mathrm{M}$ comonomer in $50 \mathrm{~mL}$ of toluene, $20 \mu \mathrm{mol} \mathrm{1-dmso,} 95^{\circ} \mathrm{C}$, $30 \mathrm{~min}$ polymerization time). In order to take advantage of the beneficial features of the azide-alkyne cycloaddition, ${ }^{[20,21]}$ a polymer-analogous reaction step ${ }^{[22]}$ was employed on the glycidyl-containing polymers (Scheme 2). Poly(ethylene-co-2-ethyl hexyl acrylate-co-glycidyl acrylate) with 6.4 mol\% of 2-ethyl hexyl- and $4.6 \mathrm{~mol} \%$ of glycidyl acrylate was treated with 10 equivalents of $\mathrm{NaN}_{3}$ and 14 equivalents of $\mathrm{NH}_{4} \mathrm{Cl}$ in a mixture of $\mathrm{DMF} /$ dioxane (v:v 2:1) at $100{ }^{\circ} \mathrm{C}$. This ratio of azide to ammonium salt was found to be necessary since lower ammonium content resulted in a partial crosslinking of the polymer. This presumably originates from an insufficient protonation of the alcoholate after glycidyl opening and subsequent anionic glycidyl polymerization. ATR-IR spectroscopy of the azidated terpolymer exhibits a characteristic absorption band of the azide at $v 2101 \mathrm{~cm}^{-1}$ with concomitant disappearance of the bands for the glycidyl at $v 909 \mathrm{~cm}^{-1}$ and $846 \mathrm{~cm}^{-1}$ (Figure S24). For crosslinking, the azidated polymer poly(ethylene-co-2-ethyl hexyl acrylate-co-azidated glycidyl acrylate) with $6.4 \mathrm{~mol} \%$ of 2-ethyl hexyl acrylate and 4.6 mol\% of azidated glycidyl acrylate was swollen in a small amount of dmso containing 0.1 equivalents of $\mathrm{Cu}(\mathrm{I}) \mathrm{Br}$, 0.2 equivalents of bipyridine and 0.5 of equivalents of nona-1,8-diyne, and heated to $90{ }^{\circ} \mathrm{C}$. Within a few minutes, a rubbery material was obtained. Copper residues were removed by dispersing the polymer in methanol. Complete conversion of azides was evidenced by ATR-IR spectroscopy. Alternatively, crosslinking was performed in the absence of any copper additive. Crosslinking apparently proceeded slower as indicated by

\subsection{Anhydride-Crosslinked Elastomers}

In addition to the polar vinyl monomers studied, functionalized norbornene was studied as a means to incorporate crosslinkable anhydride moieties. Other than most 1,2-disubstituted olefins, which react sluggishly, norbornenes can be incorporated efficiently due to their ring strain. ${ }^{[10 b, 23]}$ This has been exploited for the introduction of meldrum's acid substituents for crosslinked polyethylene by Hawker et al. ${ }^{[24]}$

Anhydrides can easily be converted to imides by reaction with amines at elevated temperatures. For this reason, norbornene anhydride was investigated towards the approach to elastomers pursued here. Norbornene anhydride is incorporated to a high extent and with high polymerization activities in copolymerization experiments (Table 3, entries 1-4). Norbornenes are unique as a comonomer in that no enhanced chain transfer occurs upon their incorporation which differs from most polar-substituted vinyl comonomers. ${ }^{[25]}$ Concerning the thermal properties of the resulting copolymers formed, the rigidity of the norbornene-derived repeat units results in relatively high glass transition temperatures (Table 3, entry 4), as observed by DSC. This limits applications of these norbornenebased polymers as elastomers (vide infra).

Crosslinking studies of the poly(ethylene-co-norbornene anhydride) polymers were performed with 1,12-dodecane diamine in refluxing xylenes for $2 \mathrm{~h}$ at $140{ }^{\circ} \mathrm{C}$. Comparative ATR IR spectroscopy of the material prior to crosslinking shows characteristic peaks for the $>\mathrm{C}=\mathrm{O}$ of the anhydride at $1859 \mathrm{~cm}^{-1}$ and $1778 \mathrm{~cm}^{-1}$ for the asymmetric and symmetric

Table 3. Co- and terpolymerization of ethylene with norbornene-endo-2,3-dicarboxylic anhydride (NA) and fluoro acrylate. a)

\begin{tabular}{|c|c|c|c|c|c|c|c|c|c|c|c|c|}
\hline Entry & $\begin{array}{l}\text { Concn. } \\
\text { (NA) [M] }\end{array}$ & $\begin{array}{c}\text { Concn. } \\
\text { (fluoro acrylate) } \\
{[\mathrm{M}]} \\
\end{array}$ & $\begin{array}{l}\mathrm{C}_{2} \mathrm{H}_{4} \\
\text { [bar] }\end{array}$ & $\begin{array}{l}\mathrm{Pd}(\mathrm{II}) \\
{[\mu \mathrm{mol}]}\end{array}$ & $\begin{array}{l}\text { Yield } \\
\text { [g] }\end{array}$ & $\begin{array}{l}\text { Inc. (NA) } \\
\left.[\mathrm{mol} \%]^{b}\right)\end{array}$ & $\begin{array}{l}\text { Inc. (fluoro } \\
\text { acrylate) } \\
{[\text { mol\% }]^{\text {b) }}}\end{array}$ & $\begin{array}{c}\text { TOF } \\
\left(\mathrm{C}_{2} \mathrm{H}_{4}\right)^{\mathrm{e})}\end{array}$ & $\begin{array}{l}\text { TOF } \\
(N A)^{\text {e) }}\end{array}$ & $\begin{array}{c}\text { TOF } \\
\text { (fluoro } \\
\text { acrylate) }{ }^{\mathrm{e})}\end{array}$ & $\begin{array}{c}\mathrm{T}_{\mathrm{m}} \\
{\left[{ }^{\circ} \mathrm{C}\right], \chi \text { (DSC) }}\end{array}$ & $\begin{array}{l}\text { Gel Content } \\
{[\%]^{\mathrm{d})}}\end{array}$ \\
\hline 1 & 0.1 & - & 5 & 10 & 4.34 & 4.0 & - & 6200 & 260 & - & $106^{\circ} \mathrm{C}, 38 \%$ & 82 \\
\hline 2 & 0.3 & - & 5 & 20 & 5.90 & 8.5 & - & 3400 & 320 & - & $82^{\circ} \mathrm{C}, 14 \%$ & 93 \\
\hline 3 & 0.6 & - & 5 & 20 & 4.36 & 13.3 & - & 2500 & 310 & - & $\mathrm{T}_{\mathrm{g}} 39^{\circ} \mathrm{C}$ & 100 \\
\hline 4 & 1.0 & - & 5 & 20 & 0.77 & 17.9 & - & 300 & 70 & - & n.m. [c] & n.m. \\
\hline 5 & 0.6 & 1.6 & 10 & 200 & 6.87 & 4.8 & 4.3 & 270 & 14 & 16 & n.m. & 93 \\
\hline
\end{tabular}

a) Polymerization conditions: toluene as solvent, 5 bar ethylene pressure, $120 \mathrm{~min}, 95{ }^{\circ} \mathrm{C}$ polymerization temperature; $100 \mathrm{~mL}$ total volume (toluene $+\mathrm{monomer}$ ), workup: precipitation in methanol, residue washed with acetone; ${ }^{b}$ Determined by ${ }^{\top} \mathrm{H}$ NMR spectroscopy; ${ }^{c}$ Intensity of olefinic chain ends too low for integration; ${ }^{d)}$ After crosslinking with 1,12-dodecane diamine; e) $\mathrm{TOF}=\mathrm{mol}\left(\right.$ monomer polymerized) $\mathrm{mol}(\mathrm{Pd})^{-1} \mathrm{~h}^{-1}$. 
stretching, respectively. The crosslinked polymer possesses asymmetric and symmetric stretching vibrations at $1769 \mathrm{~cm}^{-1}$ and $1698 \mathrm{~cm}^{-1}$ arising from the imides formed (Figure S25). ${ }^{[26]}$ No bands for residual anhydride or hydrolysis products are observed. As expected, the corresponding gel contents of poly(ethylene-co-norbornene anhydride) increase with increasing anhydride content and completely crosslinked material can be obtained (Table 3). Norbornene anhydride and fluoro acrylate were terpolymerized with ethylene (Table 3 entry 5 , and Figure S26). Crosslinking was performed as described for the copolymers poly(ethylene-co-norbornene anhydride). The gel content of the resulting elastomeric material was found to be close to quantitative with $93 \pm 5 \%$.

\subsection{Dynamic Mechanical Analysis (DMA) of the Elastomers}

The elastomeric materials obtained were subjected to dynamic mechanical analysis (DMA, at a frequency of $1 \mathrm{~Hz}$ ) in order to investigate their properties such as glass transition temperatures and crosslinking. The non-crosslinked terpolymer poly(ethylene-co-fluoro acrylate-co-siloxane acrylate) (Table 1 , entry 8) shows a drastic decline at $-31{ }^{\circ} \mathrm{C}$ in the storage and loss moduli with a concomitant maximum in the phase angle $\tan \delta$ (Figure 2). This transition is ascribed to the glass transition $\left(\mathrm{T}_{\mathrm{g}}\right)$ and is in agreement with the $\mathrm{T}_{\mathrm{g}}$ observed by DSC $\left(30 \mathrm{~K} \mathrm{~min}^{-1}\right)$ at $-30{ }^{\circ} \mathrm{C}$. Crosslinking from toluene solution with a small amount of water (toluene:water 1000:1 by volume) results in formation of an elastomeric material which possesses a glass transition temperature at $-1{ }^{\circ} \mathrm{C}$ according to the maximum in the phase angle ( $\tan \delta$ ) in DMA measurement (Figure 11, right). ${ }^{[27]}$ In contrast, for a material crosslinked in the bulk by exposure to a stream of moist hot air at $100{ }^{\circ} \mathrm{C}$ in the presence of catalytic amounts of para-toluenesulfonic acid, the maximum in $\tan \delta$ is found at $-27^{\circ} \mathrm{C}$. The gel content of this material is $97 \pm 5 \%$. A rubber plateau is observed at higher temperature in the storage modulus at a value of approximately $2.50 \mathrm{MPa}$ which gradually increases to $4.50 \mathrm{MPa}$ at $150{ }^{\circ} \mathrm{C}$. In order to shed light on the origin of the different $\mathrm{T}_{\mathrm{g}} \mathrm{s}$ observed, depending on the crosslinking procedure (from solution or in bulk), ${ }^{29} \mathrm{Si}$ MAS NMR spectra of the samples were recorded. Crosspolarization was omitted and a relaxation time of $300 \mathrm{sec}-$ onds was employed in order to assure quantitative analysis. The ${ }^{29} \mathrm{Si}$ NMR spectra exhibit two resonances at -60 and $-68 \mathrm{ppm}$ which were ascribed to $\mathrm{T}_{2}\left(\mathrm{C}\left(\mathrm{sp}^{3}\right)-\mathrm{Si}(\mathrm{OSi})_{2}(\mathrm{OH})\right)$ and $\mathrm{T}_{3}\left(\mathrm{C}\left(\mathrm{sp}^{3}\right)-\mathrm{Si}(\mathrm{OSi})_{3}\right)^{[28]}$ respectively, in a ratio of ca $2: 3$ for the terpolymer crosslinked in bulk. This ratio is $1: 4$ for the material which was crosslinked from solution (Figure 3). This demonstrates that the degree of condensation to -Si-O$\mathrm{Si}-$ crosslinks is very sensitive to the crosslinking procedure. The deviation in $\mathrm{T}_{\mathrm{g}}$ can be ascribed to higher mobility of the polymer chains in solution and a consequently higher degree of condensation.

The crosslinked terpolymers poly(ethylene-co-2-ethyl hexyl acrylate-co-glycidyl acrylate) and poly(ethylene-co-2-ethyl hexyl acrylate-co-fluoro acrylate-co-glycidyl acrylate) show a similar behavior in the modules and phase angles (Figure 4A,B). Both materials exhibit the formation of a rubber plateau in the
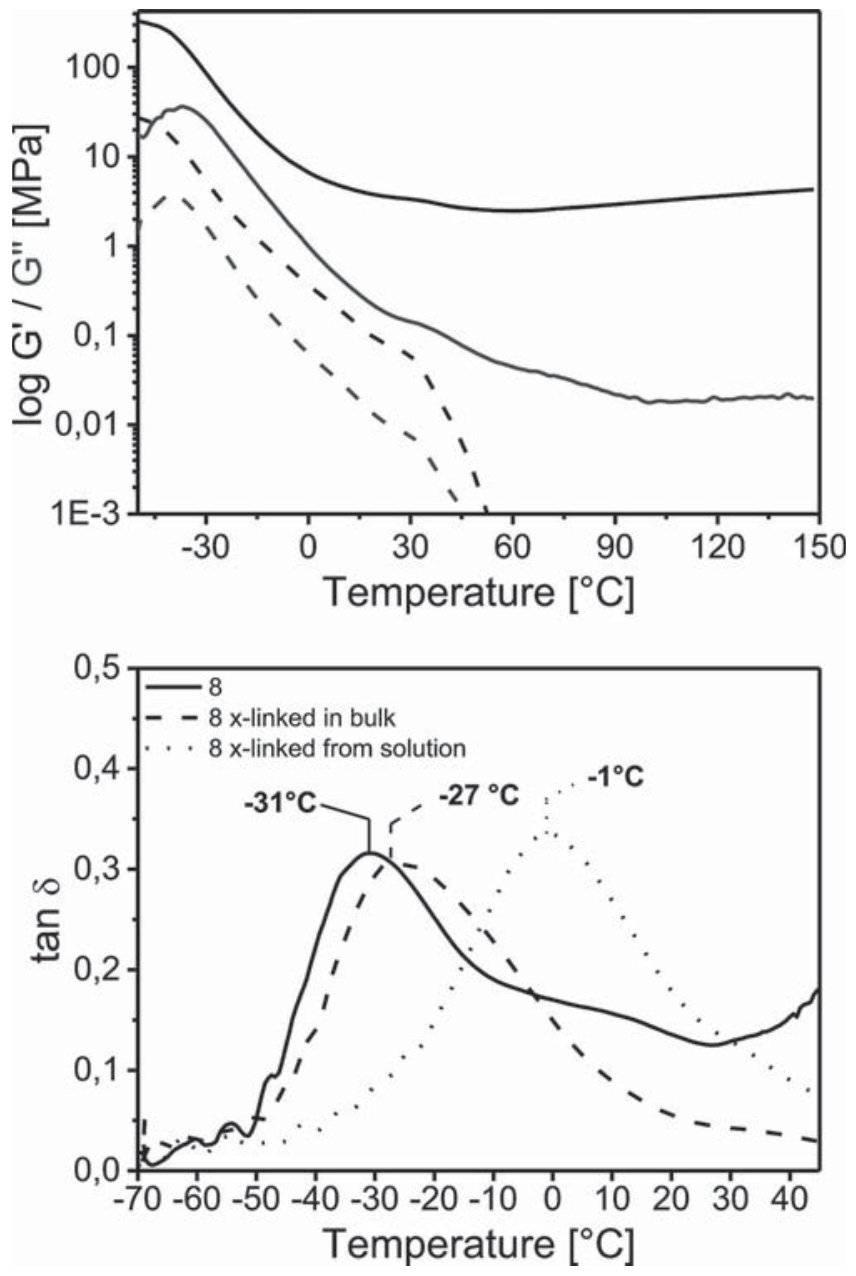

Figure 2. Top: Dynamic mechanical analysis of poly(ethylene-co-fluoro acrylate-co-siloxane acrylate) with $6.9 \mathrm{~mol} \%$ of fluoro acrylate and 8.0 mol\% of siloxane acrylate (Table 1, entry 8) (not crosslinked: dashed, crosslinked in bulk: solid) with a frequency of $1 \mathrm{~Hz}$. Storage $\mathrm{G}^{\prime}$ (black) and loss modules $G^{\prime \prime}$ (grey). Bottom: Phase angle (tan $\delta$ ) of poly (ethylene-cofluoro acrylate-co-siloxane acrylate) with $6.9 \mathrm{~mol} \%$ of fluoro acrylate and 8.0 mol\% of siloxane acrylate (Table 1, entry 8 ). Solid line: non-crosslinked; dashed line: crosslinked in bulk with moist air at $100{ }^{\circ} \mathrm{C}$; dotted line: crosslinked from toluene/water (v/v: 1000/1) solution at $100^{\circ} \mathrm{C}$.

storage modulus $\mathrm{G}^{\prime}$ with elevated temperatures in the range of 2.3 to 3.3 MPa for poly(ethylene-co-2-ethyl hexyl acrylate-coglycidyl acrylate) and 1.6 to $2.4 \mathrm{MPa}$ for poly(ethylene-co-2ethyl hexyl acrylate-co-fluoro acrylate-co-glycidyl acrylate), respectively. The phase angles for these two materials exhibit maxima at $-12{ }^{\circ} \mathrm{C}$ and $-13{ }^{\circ} \mathrm{C}$, respectively, which are attributed to the glass transition temperatures. Comparing these two measurements (Figure 4, A vs B), an additional plateau in poly(ethylene-co-2-ethyl hexyl acrylate-co-fluoro acrylate-coglycidyl acrylate) in the temperature range of $25^{\circ} \mathrm{C}$ to $50{ }^{\circ} \mathrm{C}$ is observed. This difference may be due either to residual crystallinity which originates from the polyethylene segments or to interactions of the perfluorinated alkyl side chains. ${ }^{[29]}$

Successful crosslinking was also evidenced for poly(ethyleneco-2-ethyl hexyl acrylate-co-azidated glycidyl acrylate) (6.4 mol\% 


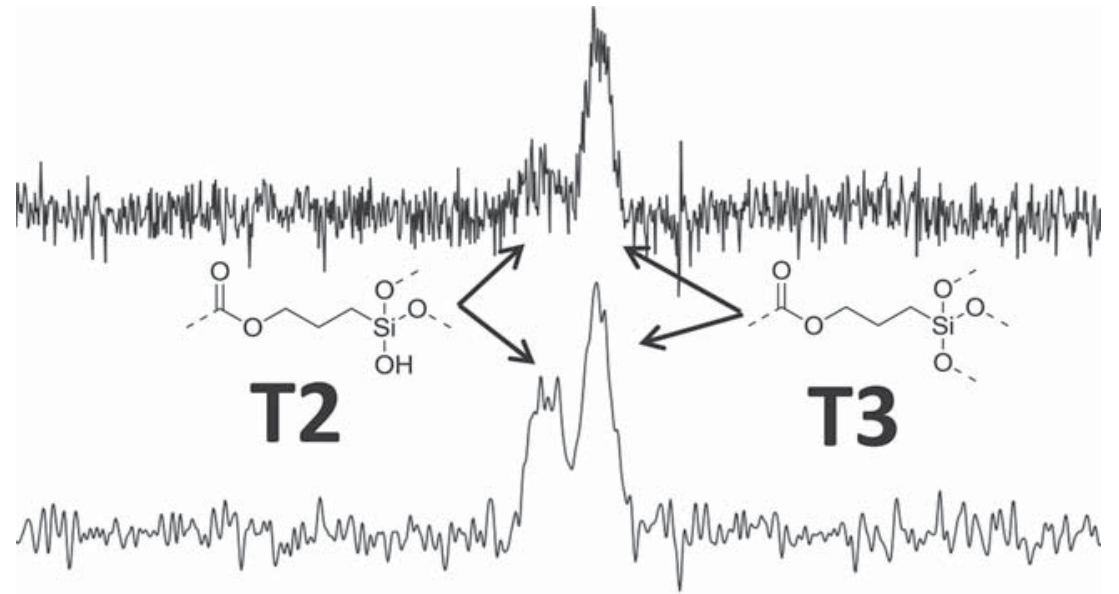

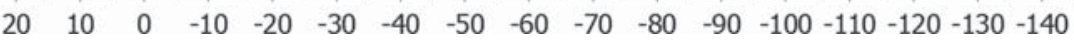

Figure 3. ${ }^{29} \mathrm{Si}$ MAS NMR spectra of crosslinked terpolymer poly(ethylene-co-fluoro acrylate-cosiloxane acrylate) (Table 1 entry 8). Top: crosslinked from toluene solution. Bottom: crosslinked in bulk. of 2-ethyl hexyl acrylate and $4.6 \mathrm{~mol} \%$ of azidated glycidyl acrylate) which was crosslinked with nona-1,8-diyne. The phase angle possesses a maximum at $-2{ }^{\circ} \mathrm{C}$ which is ascribed to the glass transition and the storage module equilibrates to a rubber plateau in the range of 0.3 to $0.5 \mathrm{MPa}$. A second, minor peak at $81{ }^{\circ} \mathrm{C}$ may arise from residual crystallinity of the polyethylene backbone (Figure $4 \mathrm{C}$ ).

DMA of the crosslinked polymer poly(ethylene-co-fluoro acrylate-co-norbornene anhydride) with $5.3 \mathrm{~mol} \%$ of incorporated fluoro acrylate and $4.8 \mathrm{~mol} \%$ of incorporated anhydride crosslinker shows the characteristic formation of a rubber plateau. For copolymers of ethylene with norbornene anhydride, rigidity of the polymer chains substantially increases with increasing norbornene content as reflected by increased glass transition temperatures. Nevertheless, crosslinked rubbery materials could be obtained with appropriate
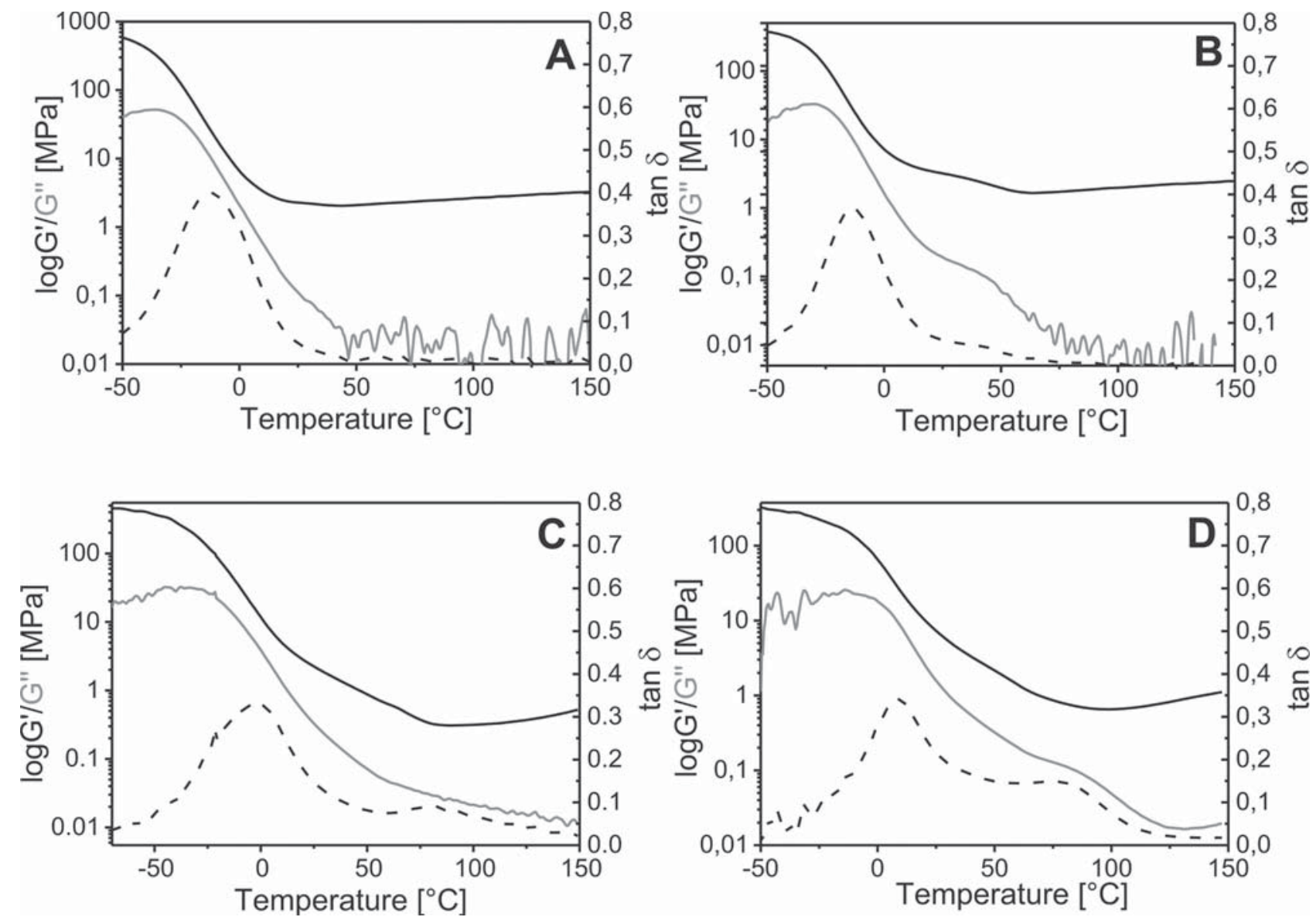

Figure 4. DMA with a frequency of $1 \mathrm{~Hz}\left(\mathrm{G}^{\prime}\right.$ black, $\mathrm{G}^{\prime \prime}$ gray; $\tan \delta$ dashed) of A) poly(ethylene-co-2-ethyl hexyl acrylate-co-glycidyl acrylate) with 7.9 mol\% of incorporated 2-ethyl hexyl acrylate and 5.8 mol\% of incorporated glycidyl acrylate crosslinked with 1,12-dodecane diamine; B) poly(ethylene-co-2-ethyl hexyl acrylate-co-fluoro acrylate-co-glycidyl acrylate) with 4.6 mol\% of incorporated 2-ethyl hexyl acrylate, 4.7 mol\% of incorporated fluoro acrylate and $6.5 \mathrm{~mol} \%$ of incorporated glycidyl acrylate crosslinked with 1,12-dodecane diamine; C) of poly (ethylene-co-2-ethyl hexyl acrylate-co-azidated glycidyl acrylate) crosslinked with nona-1,8-diyne; D) poly(ethylene-co-fluoro acrylate-co-norbornene anhydride) with 5.3 mol\% of incorporated fluoro acrylate and 4.8 mol\% of incorporated norbornene anhydride crosslinked with 1,12-dodecane diamine. 
norbornene contents. DMA measurement revealed a glass transition temperature $\left(\mathrm{T}_{\mathrm{g}}\right)$ of $9{ }^{\circ} \mathrm{C}$ (Figure 4D). The observed shoulder in the phase shift $(\tan \delta$ ) in the temperature range of 50 to $100{ }^{\circ} \mathrm{C}$ is again thought to arise from either residual mainchain crystallinity or side-chain interactions of the perfluorinated alkyl chains as observed for poly(ethylene-co-2-ethyl hexyl acrylate-co-fluoro acrylate-co-glycidyl acrylate). This is in agreement with DSC traces exhibiting a residual melting enthalpy of $36 \mathrm{~J} \mathrm{~g}^{-1}$ in this temperature range.

\subsection{Swelling Behaviour}

Perfluorinated compounds are known for their resistance towards swelling in oils and fuels. ${ }^{[1]}$ Exemplarily, the crosslinked terpolymer poly(ethylene-co-fluoro acrylate-co-siloxane acrylate) (Table 1 , entry 8 , crosslinked in bulk) which contains $6.9 \mathrm{~mol} \%$ (42 wt\%) of the perfluorinated acrylate was investigated towards its behavior in $n$-butanol and petrolether. The polymer was heated to $80^{\circ} \mathrm{C}$ for $2 \mathrm{~h}$ in the corresponding solvent. For comparison, a commercial hydrogenated butadieneacrylonitrile rubber (HNBR, acrylonitrile content 39 wt\%) and an EPDM seal rubber were treated under identical conditions. The swelling was calculated from the weight gain after treatment. The aliphatic EPDM elastomer swells by 6 wt\% in $n$-butanol and $73 \mathrm{wt} \%$ in petrolether and the HNBR by $37 \mathrm{wt} \%$ and $6 \mathrm{wt} \%$, respectively. In contrast, the terpolymer poly(ethylene-co-fluoro acrylate-co-siloxane acrylate) shows low swelling in both solvents. Weight gains of $6 \mathrm{wt} \%$ in $n$-butanol and $10 \mathrm{wt} \%$ in petrolether were determined. This demonstrates the beneficial behavior in swelling of this material in comparison to the two commercial benchmarks since swelling was marginal in both solvents. The effect of solvent exposure and resulting swelling on the elastomeric behavior was further evaluated by Shore A hardness. While the non-swollen polymer exhibits a value of 88 , upon swelling with petrolether hardness decreases to a value of 70 as expected due to a gain of flexibility of the polymer chains. However, evaporation of the swollen polymer results in a value of 85 which agrees with the original value of 88 within the experimental error. This evidences that no irreversible change in polymer structure caused by heating but merely swelling with solvent occurred indeed.

\section{Conclusion}

Insertion polymerization of functionalized vinyl monomers allows for the direct synthesis of saturated polar-substituted elastomers. This circumvents additional post-polymerization functionalization or hydrogenation steps. The approach has been demonstrated to be compatible with a diverse range of different cross-linking chemistries. This is important, as it is obviously a key requirement for the preparation of novel elastomeric materials, and there is no single generally preferred crosslinking chemistry but rather this choice depends on the details of a given processing method and application. Crosslinking of glycidyl- or anhydride-functionalized polymers with amines, via incorporated siloxanes or azide-alkyne coupling occurs efficiently, as concluded from observation of the conversion of the reacting groups and from gel contents, and yields elastomeric materials. Though even lower glass transition temperatures may be desirable for some applications, it can be noted that materials with glass transition temperatures well below room temperature are accessible. Norbornene anhydride as a comonomer stands out concerning its advantageously high incorporation ratio under given copolymerization conditions, and it introduces polar cross-linkable groups without compromising polymer molecular weights. However, the rigidity of the bicyclic repeat units results in unfavorably high glass transition temperatures. As anticipated, appropriately substituted polymers show a pronounced resistance to apolar hydrocarbon solvents, which are ubiquitous e.g. in automotive applications. To our knowledge, this novel route to elastomers is also the first example of detailed studies of materials properties of polymers from polar vinyl monomer insertion copolymerization.

\section{Acknowledgments}

Financial support of this work by Lanxess AG is gratefully acknowledged. DMA measurements were kindly provided by Lanxess AG.

[1] Ullmann's Encyclopedia of Industrial Chemistry, Wiley-VCH, Weinheim 2005

[2] a) E. Drent, R. van Dijk, R. van Ginkel, B. van Oort, R. I. Pugh, Chem. Commun. 2002, 744; b) D. Guironnet, P. Roesle, T. Rünzi, I. Göttker-Schnetmann, S. Mecking, J. Am. Chem. Soc. 2009, 131, 422.

[3] W. Weng, Z. Shen, R. F. Jordan, J. Am. Chem. Soc. 2007, 129, 15450.

[4] a) K. M. Skupov, P. R. Marella, M. Simard, G. P. A. Yap, N. Allen, D. Conner, B. L. Goodall, J. P. Claverie, Macromol. Rapid Commun. 2007, 28, 2033; b) T. Friedberger, P. Wucher, S. Mecking J. Am. Chem. Soc. 2012, 134, 1010.

[5] S. Luo, J. Vela, G. R. Lief, R. F. Jordan, J. Am. Chem. Soc. 2007, 129, 89463.

[6] C. Bouilhac, T. Rünzi, S. Mecking, Macromolecules 2010, 43, 3589.

[7] S. Ito, M. Kanazawa, K. Munakata, J. Kuroda, Y. Okumura, K. Nozaki, J. Am. Chem. Soc. 2011, 133, 1232.

[8] T. Kochi, S. Noda, K. Yoshimura, K. Nozaki, J. Am. Chem. Soc. 2007, 129, 8948.

[9] S. Ito, K. Munakata, A. Nakamura, K. Nozaki, J. Am. Chem. Soc. 2009, 131, 14606.

[10] a) T. Rünzi, D. Fröhlich, S. Mecking, J. Am. Chem. Soc. 2010, 132, 17690; b) J.-C. Daigle, L. Piche, J. P. Claverie, Macromolecules 2011, 44, 1760.

[11] a) A. Berkefeld, S. Mecking, Angew. Chem. Int. Ed. 2008, 47, 2538; b) A. Nakamura, S. Ito, K. Nozaki, Chem. Rev. 2009, 109, 5215; c) A. Nakamura, T. M. J. Anselment, J. P. Claverie, B. L. Goodall, R. F. Jordan, S. Mecking, B. Rieger, A. Sen, P. W. N. M. van Leeuwen, K. Nozaki, Acc. Chem. Res. 2013, DOI: 1439. 
[12] P. Wucher, P. Roesle, L. Falivene, L. Cavallo, L. Caporaso, I. GöttkerSchnetmann, S. Mecking, Organometallics 2012, 31, 8505

[13] Late Transition Metal Polymerization Catalysis (Eds: B. Rieger, L. S. Baugh, S. Kacker, S. Striegler), Wiley-VCH, Weinheim 2003 pp.101-154

[14] T. Rünzi, U. Tritschler, P. Roesle, I. Göttker-Schnetmann, H. Möller, L. Caporaso, A. Poater, L. Cavallo, S. Mecking, Organometallics 2012, 31, 8388.

[15] DIN ISO 6427, Beuth Verlag, 1998 "Plastics - Determination of matter extractable by organic solvents".

[16] Epoxy Resins: Chemistry and Technology (Ed: Clayton A. May), 2nd Ed., Marcel Dekker, New York 1988.

[17] Infrared and Raman Characteristic Group Frequencies (Ed: George Socrates), 3rd Ed., John Wiley \& Sons Ltd., Chichester 2004.

[18] Y. Iwakura, F. Toda, T. Ito, K. Aoshima, Makromol. Chem. 1967, 104, 26.

[19] M. H. Espinosa, P. J. O. del Toro, D. Z. Silva, Polymer 2001, 42, 3393.

[20] R. Huisgen, Proc. Chem. Soc. 1961, 357.

[21] H. C. Kolb, M. G. Finn, K. B. Sharpless, Angew. Chem. Int. Ed. 2001 113, 2056.
[22] N. V. Tsarevsky, S. A. Bencherif, K. Matyjaszewski, Macromolecules 2007, 40, 4439.

[23] P. Wehrmann, M. Zuideveld, R. Thomann, S. Mecking, Macromolecules 2006, 39, 5995.

[24] F. A. Leibfarth, Y. Schneider, N. A. Lynd, A. Schultz, B. Moon, E. J. Kramer, G. C. Bazan, C. J. Hawker, J. Am. Chem. Soc. 2010, 132, 14706.

[25] A. Ravasio, L. Boggioni, I. Tritto, Macromolecules 2011, 44, 4180.

[26] T. T. M. Phan, A. J. DeNicola, L. S. Schadler, J. Appl. Polym. Sci. 1998, 68, 1451.

[27] The corresponding storage modulus $G^{\prime}$ equilibrates in the range of 0.2 to $0.3 \mathrm{MPa}$.

[28] Similar chemical shifts for $T_{2}$ and $T_{3}$ and a delay time of $100 \mathrm{~s}$ for quantitative analysis were reported in: Ö. Dag, Y. Ishii, T. Asefa, M. J. MacLachlan, H. Grondey, N. Coombs, G. A. Ozin, Adv. Funct. Mater. 2001, 11, 213.

[29] Fluoro acrylate homopolymer formed by free-radical polymerization possesses a melting temperature of $T_{m}=56{ }^{\circ} \mathrm{C}$ according to DSC measurements. 